\title{
Mathematical Thinking and Task Design
}

\author{
SINÉAD BREEN AND ANN O'SHEA
}

\begin{abstract}
Mathematical thinking is difficult to define precisely but most authors agree that the following are important aspects of it: conjecturing, reasoning and proving, abstraction, generalization and specialization. However, recent studies have shown that many sets of mathematical tasks produced emphasize lower level skills, such as memorization and the routine application of algorithms or procedures. In this paper we survey the literature on the design and use of tasks that aim to encourage higher level aspects of mathematical thinking in learners of mathematics at all levels. The frameworks presented here aim to guide task designers when writing a set of exercises.
\end{abstract}

\section{INTRODUCTION}

There are many different definitions and interpretations of the term mathematical thinking. We all have an intuitive feel for what this term means and whether we have formulated a clear definition of it or not, we probably aim to promote mathematical thinking in our students. In this article, we will look at different definitions of the term and at some suggestions from the literature as to how this type of thinking might be fostered in students, through the use of mathematical tasks. In this paper, the term task will refer to both homework problems and classroom activities where the student is asked to work on an exercise on their own or in a group. To this end, we will discuss features that have been suggested as being desirable in mathematical tasks and survey various frameworks proposed to aid the design of tasks, reporting briefly on some studies where these frameworks have been used. We will also consider the findings of a number of authors on the types of tasks that have been assigned to students taking mathematics courses at upper second-level and early undergraduate level. Finally, we pass on some advice garnered from 
the literature in relation to factors that should be attended to when implementing mathematical tasks in order to protect their integrity.

\section{Mathematical Thinking}

Let us start with the notion of mathematical proficiency as used by the Mathematics Learning Study Committee of the US National Research Council [6]. For them, mathematical proficiency is what allows people to learn mathematics successfully and they believe that this has five strands: conceptual understanding; procedural fluency; strategic competence (the ability to formulate and solve mathematical problems); adaptive reasoning (capacity for logical thought, reflections and justification); productive disposition (seeing mathematics as worthwhile and being confident in one's own abilities), (p.116). The authors claim that these five strands are interwoven and that all five should be encouraged and developed together. The focus in [6] is on school mathematics. At third level, the notion of advanced mathematical thinking is often considered. There is some debate as to whether this term means thinking about advanced mathematics or thinking about any mathematics in an advanced way. David Tall [19] claims that the distinguishing features of advanced mathematical thinking are abstraction, and the insistence on proof rather than justification.

Many authors agree that the mathematical practices and thinking to be encouraged in learners of mathematics should mirror the practices of professional mathematicians. For instance, Hyman Bass [1] speaks about the mathematical practices or habits of mind of research mathematicians and argues that these practices such as experimentation, reasoning, generalization, the use of definitions and the use of mathematical language can be fostered at any stage in the education system. Mason and Johnston-Wilder [9] provide a detailed list of words they believe denote processes and actions that mathematicians employ when they pose and tackle mathematical problems: "exemplifying, specializing, completing, deleting, correcting, comparing, sorting, organizing, changing, varying, reversing, altering, generalizing, conjecturing, explaining, justifying, verifying, convincing, refuting" (p.109). They propose that questions posed to students should draw on these words to enable students to experience aspects of mathematical thinking. Acquiring a mathematical disposition is how Henningsen and Stein [5] speak of students' 
learning of mathematics - such a disposition being characterized by activities such as "exploring patterns to understand mathematical structures and underlying relationships; using available resources effectively and appropriately to formulate and solve problems; making sense of mathematical ideas, thinking and reasoning in flexible ways" (p.525), in addition to those mentioned above.

However, in popular culture, it seems that mathematics is often associated with certainty - Lampert [8] describes how school experience can shape the cultural belief that "doing mathematics means following the rules laid down by the teacher; knowing mathematics means remembering and applying the correct rule when the teacher asks a question; and mathematical truth is determined when the answer is ratified by the teacher" (p.32). She points out that the activity of doing mathematics is different to what is recorded once it is done and she has worked towards bringing the practice of doing mathematics in school closer to what it means to do mathematics within the discipline itself. This, she believes, involves students at all levels of schooling engaging in activities similar to those in which mathematicians engage (in agreement with [1], [5], [9]).

Bell [2] asserts that most uses of mathematics involve a cycle of mathematization (that is, recognizing the relevance of some mathematical relationship in a given situation and expressing it symbolically), manipulation and interpretation. He laments the fact that traditional mathematics instruction has assumed that the part of this process that needs most teaching is the phase of manipulation and so traditional school lessons have consisted of demonstration of a single technique followed by practice with a variety of numbers. He too believes that the main lesson experience should instead be one of genuine and substantial mathematical activities bringing into play the sort of strategies mentioned above (abstracting, formulating questions etc.).

\section{Types of TAsks ObServed}

In [14] Sangwin takes a different approach. He maintains that assessment drives what and how mathematics is learned and so "any attempt to elaborate on what is meant by mathematical skills must be based on an analysis of what in reality we ask students to do" (p.814). In collaboration with Pointon, he developed a mathematical 
question taxonomy in order to undertake a classification of coursework questions. Table 1 illustrates this taxonomy.

\begin{tabular}{|l|}
\hline 1. Factual recall \\
\hline 2. Carry out a routine calculation or algorithm \\
\hline 3. Classify some mathematical object \\
\hline 4. Interpret situation or answer \\
\hline 5. Prove, show, justify - (general argument) \\
\hline 6. Extend a concept \\
\hline 7. Construct an instance \\
\hline 8. Criticize a fallacy \\
\hline
\end{tabular}

TABLE 1. Mathematical question taxonomy of Pointon and Sangwin $[11,14]$

Successful completion of tasks following 1-4 of Table 1 are characteristic of 'adoptive learning' in which students engage in an essentially reproductive process requiring the application of well-understood knowledge in bounded situations [14] — that is, the students behave as 'competent practitioners'. While questions in classes 4-8 of Table 2 typically require higher cognitive processes such as creativity, reflection, criticism, and would be characterized as 'adaptive learning', requiring students to behave as 'experts'.

This taxonomy was used to classify a total of 486 course-work and examination questions used on two first year undergraduate mathematics courses, leading to the finding that "(i) the vast majority of current work may be successfully completed by routine procedures or minor adaption of results learned verbatim and (ii) the vast majority of questions asked may be successfully completed without the use of higher skills" ([14] p.8). In fact, further details given in [11] show that $61.4 \%$ of all questions inspected related to class 2 of Table 1 while only $3.4 \%$ of questions related to classes $6-8$.

Others have also undertaken work on investigating the types of tasks that are assigned to students as homework or that appear on examinations. In [4], Boesen, Lithner and Palm considered tasks from Swedish national second level high stakes examinations and classified them according to how familiar they were to students. They used textbooks to decide if the tasks are familiar or not. They also characterized the types of reasoning that students might use 
to solve problems: imitative reasoning (using memorization or wellrehearsed procedures); creative mathematically founded reasoning (novel reasoning with arguments to back it up and anchored in appropriate mathematical foundations). Not surprisingly, they found that often no conceptual understanding was needed to solve familiar tasks. Boesen et al claim that exposure to familiar tasks alone affects students' ability to reason and so influences student learning. Bergqvist [3] analyzed 16 examinations from introductory courses in Calculus in four Swedish universities. She found that $70 \%$ of the exam questions could be solved using imitative reasoning alone and that 15 of the 16 examinations could be passed without using creative reasoning.

\section{Purposes of Tasks and Frameworks for Task Design}

Polya, in his preface to How to Solve It [12], states

'Thus, a teacher of mathematics has a great opportunity. If he fills his allotted time with drilling his students in routine operations he kills their interest, hampers their intellectual development, and misuses his opportunity. But if he challenges the curiosity of his students by setting them problems proportionate to their knowledge, and helps them to solve their problems with stimulating questions, he may give them a taste for, and some means of, independent thinking.' (p.v).

How might mathematical tasks be designed in order to make best use of the opportunity Polya describes? Mason and Johnston-Wilder [9] define the purpose of a mathematical task as being "to initiate mathematically fruitful activity" (p.25) which entails harnessing learners' innate abilities to stress and ignore, specialize and generalize, distinguish and connect, imagine and express, conjecture and convince, organize and characterize. In their opinion, tasks should involve a range of possibilities and offer students opportunities to discuss ideas and to make choices, in order for students to view mathematics as a constructive enterprise. In addition, tasks should be chosen to enable learners to encounter significant mathematical ideas and themes, and should be appropriately challenging without being over-taxing. An individual task may have one of a number of intentions - according to Mason and Johnston-Wilder these are providing a context for practising ideas met previously, providing a context to encounter new ideas, acting as revision or consolidation, 
prompting reflection, prompting the connection and integration of various ideas.

Stein et al [16] also emphasize the importance of the type of mathematical tasks presented to students as these highly influence the kinds of thinking processes in which they engage, their level of engagement, and, thus, the learning outcomes achieved. Tasks with which students engage determine not only what substance they learn but, more importantly, how they come to think about, develop, use and make sense of mathematics. As a result, they should be exposed to meaningful and worthwhile mathematical tasks. Truly problematic tasks should require students to impose meaning and structure, to make decisions about what to do and how to do it, and to interpret the reasonableness of their actions and solutions. They contend that such tasks are characterized by features such as: having more than one solution strategy; being capable of being represented in multiple ways; demanding that students communicate and justify their processes and understandings in written and/or oral form.

Writing in 1993, Krainer [7] described the move away from traditional methods of teaching to one in which students are more active and are given the opportunity to create their own knowledge. He says '...learners should be seen not only as consumers but also producers of knowledge. The teacher's task is to organize an active confrontation of the pupils with mathematics. Powerful tasks are important points of contact between the actions of the teacher and those of the learner' (p.68). He describes some properties of powerful tasks: tasks should have connections with other tasks and areas of mathematics; tasks should generate other interesting questions; tasks should involve actions that promote concept formation; tasks should be structured so that acting and reflecting are closely linked. In the remainder of his paper Krainer [7] reports on a set of 69 tasks written by him to encourage students to think about the concept of angle. He describes 5 of the tasks in detail, giving learning objectives for each one and explaining the connections with other tasks.

Bell [2] also describes some desirable properties or features of mathematical tasks. Tasks should be connected so that knowledge is more easily retained; an element of feedback should be incorporated (e.g. self-verification) for immediate detection of misconceptions; a reflection and review phase should be built-in to provide for the expression and sharing of different understandings and help place new knowledge within the broader field of mathematics. 
More recently, Swan [18] has created a framework of 5 task types that he believes foster conceptual understanding at second level. They are classifying mathematical objects (asking students to devise or apply a classification); interpreting multiple representations (drawing links and developing mental images for concepts); evaluating mathematical statements (asking students whether statements are always, sometimes or never true, and developing proofs); creating problems (asking students to create problems for the class); analyzing reasoning and solutions (diagnosing errors and comparing solutions). The tasks described are designed as classroom activities. He asserts that teaching is more effective when rich tasks are used. He says 'The tasks we use should be accessible, extendable, encourage decision-making, promote discussion, encourage creativity, encourage 'what if' and 'what if not?' questions' (p.8). Along with the use of tasks, he contends that teaching for conceptual understanding is more effective when it builds on the students' previous knowledge, confronts difficulties rather than avoiding them and exposes common misconceptions. He also believes that students should be encouraged to talk and write about mathematical ideas, that teachers should emphasize reasoning and not 'answer-getting'. This paper also describes the design of one task in detail.

Schoenfeld [15] created a framework for balanced assessment in an NSF-funded project. His framework introduces seven dimensions under which tasks could be measured: content (including procedure and technique, representations and connections); thinking processes; student products; mathematical point of view; diversity; circumstances of performance; pedagogics-aesthetics. Each dimension is further refined, for example, the student products dimension considers the type of work the students will produce as a result of the task such as a model, an investigation, an explanation, a decision and justification, a problem solution, and/or the exhibition of a technique.

Schoenfeld's emphasis is on balance [15] and he recognizes that any one task could not foster all types of thinking, for example, but that when a set of tasks is being designed (whether they be homework assignments, examination questions or classroom activities) one should aim to cover as many different dimensions as possible. Mason and Johnston-Wilder [9] also advocate a "mixed economy" (p.6) in which learners are given a variety of types of tasks to develop mathematical thinking; Sangwin [13] and Bell [2] reinforce this viewpoint. 
In general, the types of tasks considered by the authors mentioned in this section concern asking students to generalize and specialize, generate examples, make conjectures, reason, make decisions, explore, make connections, and reflect. Maria Meehan [10] has already written in this journal about example generation. Other ways of creating tasks on these topics can be found in Watson and Mason's [20] book Questions and Prompts for Mathematical Thinking. For example, to write tasks on generalization they suggest that questions like 'What happens in general?', 'Of what is this a special case?', 'What can change and what has to stay the same so that ... is still true?' could be used. Tasks like the ones mentioned here can be adapted and assigned to students at all levels.

\section{IMPLEMENTATION OF TASKS}

Swan [17] describes using some of his tasks in a professional development course for mathematics teachers which ran for 6 months and had participants from 44 different schools in the UK. He gives examples of the 5 task types described in the previous section. The teachers used these tasks in their own classrooms and reported changes in their beliefs and practices. The tasks encouraged the teachers to use more challenging examples than normal, to confront students with conceptual obstacles and to encourage collaboration in their classes.

In reaction to the analysis of tasks Sangwin undertook ([14]), which showed how rarely students were asked to think in creative ways, he developed a number of questions in which students were asked to 'create an instance' — that is, generate an example or provide an object satisfying certain mathematical properties. Although typically there will be many correct answers to such a question and no general method for constructing an instance, Sangwin describes how such questions may be assessed in practice without the imposition on staff of an onerous marking load [14]. He also reports that feedback from a small number of students, with whom the questions were trialled, showed they had a mature understanding of the purposes of these questions.

Bell [2] states that a demonstration-plus-exercises method of teaching risks failing to make contact with students' actual knowledge and thus makes it more difficult for the new knowledge to be embedded in the students' existing cognitive structure. Instead he recommends that tasks should be attempted by students initially and only when 
their responses have been given should the teacher intervene to offer hints or help towards a solution. He also notes that effective methods of teaching involve crucial management of the learning situation by the teacher, for instance, by adjusting the challenge of a task presented to keep it at an appropriate level for all learners.

In working to challenge conventional ideas about 'doing mathematics' at school, Lampert [8] based her approach on the assumption that students would not learn a different way of thinking about what it means to do mathematics simply by being told what to do or having mathematical problems explained to them. Instead she modelled and demonstrated mathematical thinking in a public manner in her classroom, engaging in mathematical arguments with her students and allowing such arguments to "wander around in various mathematical terrain" (p.41), encouraging the students to make conjectures and to muster appropriate evidence to support or challenge each others' assertions.

Henningsen and Stein [5] warn that it is not enough for a teacher to select and appropriately set-up worthwhile mathematical tasks: he/she must also proactively and consistently support students' cognitive activity in order to ensure that the complexity and cognitive demands of the tasks are not reduced during implementation. Furthermore, Stein et al [16] found that those mathematical tasks which were most cognitively demanding at the design phase (e.g. involving conjecturing, justifying, interpreting) were most likely to decline into somewhat less-demanding activities in implementation. Their research found that tasks that are most likely to maintain high-level cognitive engagement are those that are built on students' prior knowledge. Mason and Johnston-Wilder [9] also warn that there may be a mismatch between the intentions of the author or designer of a task and the motives of a learner. Tasks may be altered, often unconsciously, so that the intentions of a task are not effectively translated in its implementation and therefore the proposed learning outcomes are not attained. For instance, learners may reconstruct a task for themselves so that it becomes something they can do, or by issuing instructions in order to make a task as accessible as possible for his/her students, a teacher might undermine the very purpose of a task. 


\section{Conclusion}

In order to develop mathematically, it is necessary for learners of mathematics not only to master new mathematical content but also to develop a wide range of thinking skills. Most courses emphasize content but students are often expected to pick up mathematical habits of mind on their own. This is sufficient for only a limited proportion of students. One way that the mathematical community could aid students would be to assign a wider range of tasks which would develop their mathematical thinking skills. In this paper we have surveyed some of the mathematics education literature on this topic and for those who wish to learn more and actively incorporate these ideas into their teaching, we hope that the references in this paper will be a good starting point.

\section{REFERENCES}

[1] H. Bass, Mathematics, mathematicians and mathematics education, Bulletin of the American Mathematical Society, 42, (2005), 417-430.

[2] A. Bell, Principles for the design of teaching, Educational Studies in Mathematics, 24(1) (1993), 5-34.

[3] E. Bergqvist, Types of reasoning required in university exams in mathematics, Journal of Mathematical Behavior, 26 (2007), 238-370.

[4] J. Boesen, J. Lithner and T. Palm, The relation between types of assessment tasks and the mathematical reasoning students use, Educational Studies in Mathematics, 75 (2010), 89-105.

[5] M. Henningsen, and M.K. Stein, Mathematical tasks and student cognition: Classroom-based factors that support and inhibit high-level mathematical thinking and reasoning, Journal for Research in Mathematics Education, 25(5) (1997), 524-549.

[6] J. Kilpatrick, J. Swafford, and B. Findell, (Eds.) Adding it up: helping children learn mathematics (2001) Washington, D.C.: National Academy Press.

[7] K. Krainer, Powerful tasks: A contribution to a high level of acting and reflecting in mathematics instruction, Educational Studies in Mathematics, 24 (1993), 65-93.

[8] M. Lampert, When the problem is not the question and the solution is not the answer: knowing and teaching mathematics, American Educational Research Journal, 27(1) (1990), 29-63.

[9] J. Mason, and S. Johnston-Wilder, Designing and Using Mathematical Tasks, Tarquin, 2004.

[10] M. Meehan, Students meeting advanced mathematics for the first time - can mathematics education research help?, Irish Mathematics Society Bulletin, 49, (2002), 71-82. 
[11] A. Pointon, and C. Sangwin An analysis of undergraduate core material in the light of hand-held computer algebra systems, International Journal of Mathematical Education in Science and Technology, 34(5) (2003), 671-686.

[12] G. Polya, How to Solve It, (1945), Princeton University Press.

[13] C. Sangwin, On building polynomials, Mathematical Gazette, (2005), 1-9.

[14] C. Sangwin, New opportunities for encouraging higher level mathematical learning by creative use of emerging computer assessment, International Journal of Mathematical Education in Science and Technology, 34(6) (2003), 813-829.

[15] A. H. Schoenfeld, A Framework for Balance: Balanced Assessment Project, Unpublished document, prepared for NSF-sponsored Calculus assessment workshop (1992).

[16] M.K. Stein, B.W. Grover, and M. Henningten, Building student capacity for mathematical thinking and reasoning: An analysis of mathematical tasks used in reform classrooms, American Educational Research Journa 33(2) (1996), 455-488.

[17] M. Swan, The impact of task-based professional development on teachers' practices and beliefs: a design research study, Journal of Mathematics Teacher Education, 10 (2007), 217-237.

[18] M. Swan, Designing a multiple representation learning experience in secondary algebra, Educational Designer, 1 (2008), 1-17.

[19] D. Tall, The nature of advanced mathematical thinking, Proceedings of Psychology of Mathematics Education Conference, Hungary (1988).

[20] A. Watson and J. Mason, Questions and Prompts for Mathematical Thinking, (1998), Derby, Association of Teachers of Mathematics.

Sinéad Breen,

CASTeL,

St Patrick's College,

Drumcondra, Ireland

sinead.breen@spd.dcu.ie

\author{
Ann O'Shea, \\ Department of Mathematics, \\ National University of Ireland, \\ Maynooth, Ireland \\ ann.oshea@nuim.ie
}

Received on 15 November 2010. 